\title{
A INSTABILIDADE DO CAPITALISMO: A VISĀO DE KEYNES E SCHUMPETER
}

\author{
MARCIA REGINA GABARDO DA CAMARA ${ }^{a}$
}

\section{RESUMO}

A instabilidade do capitalismo é reconhecida pela maioria das correntes teóricas da economia e foi muito explorada nos anos 70 com a redescoberta do "verdadeiro" Keynes e nos 80, com os estudos exploratórios sobre Schumpeter. Este trabalho é uma tentativa de analisar a instabilidade capitalista em uma linguagem acessivel e clara, de caráter introdutório. As versões desenvolvidas neste artigo são a vertente schumpeteriana e a Keynesiana da instabilidade capitalista.

PALAVRAS-CHAVE: Instabilidade capitalista; Desenvolvimento e crise; Ciclo económico; Schumpeter, Keynes

\section{1 -- A INSTABILIDADE DO CAPITALISMO SEGUNDO KEYNES}

Na Teoria Geral, Keynes ${ }^{(1)}$ desenvolve o argumento que as flutuações de renda e de emprego são inerentes à economia capitalista; a instabilidade espraia-se pela economia a partir do estado de incerteza em que as decisões de investir são tomadas.

Keynes identifica a questão da instabilidade do inves. timento como central para sua análise e o problema é trata. do em dois níveis. $O$ primeiro refere-se à natureza intrinsecamente instável da lógica das decisões de investir que se baseiam em evidências sujeitas a mudanças bruscas e violentas. Os elementos permitem a Keynes delinear um quadro geral da lógica financeira e das decisôes de investimento privado (Possas, 1987).

O segundo nível de análise refere-se especificamente à crise capitalista, fenômeno distinto do ciclo economico, mas que está subordinado a ele. Keynes teorizou sobre o ciclo a partir do Tratado sobre a Moeda. A sistematização de Keynes (1983) contribuiu para a compreensão da fase da crise, a partir da ótica da demanda efetiva.

Para compreender a extensão da contribuição de Keynes é necessário se enfronhar na obra-prima do autor e desvendar seus mistérios, ressaltando as características que permitiram ao autor aprofundar o conceito de economia monetária ${ }^{(2)}$.

A integração da moeda à teoria de produção permitiu-the formular a mais razoável das explicações para as flutuações inerentes ao capitalismo e do contrapeso entender as flutuações do emprego em economias capitalistas maduras.

Para Keynes (1983), a produção capitalista é realizada por firmas motivadas pelo lucro que se concretiza monetariamente. A firma busca a acumulação (de bens) que permitirá expandir sua receita em dinheiro, que possibilitará a troca que só se realizam em moeda.

Mas nesta economia caracterizada pelo estado de confiança flutuante, a moeda adquire outros papéis que não o de meio de troca. As condições incertas (falta de informações ou informação incompleta) sob que operam os agentes econômicos os impulsionam para a formação de expectativas, a não neutralidade da moeda (a moeda como um véu, meio de trocal e a existência de um lapso de tempo entre a decisão e os resultados condicionam a dicotomia entre as variáveis reais e as monetárias.

As principais funções da moeda são servir como meio de troca, unidade de conta e reserva de valor, meio de conservação da riqueza a noção de moeda enquanto ativo revoluciona a teoria econômical(3).

a - Departamento de Economia - Universidade Estadual de Londrina

b- A autora agradece os valiosos comentários cos assessores científicos da Revista Semina

(1) - Existem duas leituras de Keynes (1983), a de Hicks (1937) em "Mr. Keynes and the Classics", que domina os manuais da economia e é denominada de modelo IS-LM e a interpretação alternativa de Minsky (1975), Kregel, Chick (1983) e outros. Hicks (1974. 1977) reconsiderou suas opinióes nas obras da década de 70. Para maiores detalhes ver Mollo (1988) e Bier (1988).

(2) - A formulação do conceito de economia monetária se inicia no Treatise on Monev e nos Tracts of Monetary Reform.

(3) - As funções da moeda eram conhecidas: meio de troca, unidade de conta e reserva de valor. Keynes é o primeiro a destacar que ao se desfazerem do dinheiro que retêm - sua riqueza monetária -, as pessoas exigem um prêmio.

146 
Carvalho $(1986, p .94)$ explica que a flexibilidade que a moeda permite na escolha dos ativos deve-se ao fato de ser bem aceita tanto para o pagamento de dívidas quanto para a compra de bens e ativos financeiros; ela representa liquidez imediata, "não está referida a nenhum objeto em particular e não tem data especifica para sua realização".

A medida que cresce a incerteza na economia a moeda se torna mais flexível, permite maior liquidez e um retorno, como qualquer outro ativo. Uma das características que tornam a moeda peculiar é a sua elevada elasticidade de procura como reserva de valor, substituindo outros ativos e retendo poder de compra no tempo, em economias não expostas a experiéncia prolongada de explosões nos niveis de preços.

Mas a moeda possui uma baixa elasticidade de substituição, por ser o ativo mais líquido, cujo o retorno é relativamente rígido para baixo em comparação aos demais, o que the proporciona maior aceitabilidade em relação aos ativos financeiros e reais. A principal evidência dessa inelasticidade são os patamares das taxas de juros. A moeda, segundo Keynes (1936), possui baixa elasticidade de produção pois somente o Banco Central pode produzi-ia ${ }^{(4)}$

Como a moeda não pode ser substituída, não pode ser produzida pelo setor privado, à medida que a incerteza aumenta, torna-se o substituto por excelencia dos bens reais Isto porque os ativos de maior liquidez oferecem baixa ou quase nenhuma renda, enquanto os bens reais (de capital) oferecem elevadas expectativas de lucro para compensar sua iliquidez.

A possibilidade de flutuação da atividade econômica e do emprego surge:

porque em determinadas situaçöes detentores de ativos deixam de comprar bens de capital e,desviam sua demanda para objetos que nao empregam trabalho, como no caso, a moeda, - e que não podem ser substituidos por objetos que empregam trabalho - (..) gera (ndo) desemprego (Carvalho, 1986, p.97).

Mas se a moeda introduz a instabilidade na economia ao permitir o vazamento/interrupção do fluxo de renda, ela também é responsável por parcela da estabilidade, dandothe um caráter dicotômico. A estabilidade que a moeda transmite às atividades econômicas tem suas raízes nos contratos que são efetuados em unidades monetárias.

A escolha do portfólio dos agentes econômicos é a origem da instabilidade porque sob condições de incerteza o retorno do ativo mais líquido, os juros, será sensivelmente superior aos demais retornos e deslocará a demanda em detrimento dos ativos de capital real - comprometimento definitivo, irreversível dos recursos aplicados ${ }^{(5)}$.

Mas a existéncia de contratos estabiliza e permite o funcionamento das economias de mercado, ao garantir controle sobre os custos diretos da produção e os recursos comprometidos, vinculados à atividade produtiva, liberando os dirigentes para escolher a forma de melhor financiar os ativos - no primeiro caso, a expectativa de incerteza se reduz e no segundo ela se amplia.

Os contratos permitem a socialização das incertezas e transmitem estabilidade, na hipótese de uma expectativa favorável à estabilidade do poder de compra da moeda no tempo. Os contratos são efetuados em moeda porque os valores nominais estipulados representam poder de compra futuro. Na presença de expectativas inflacionárias, a estabilidade se dissolve ao reduzir a amplitude e o prazo dos contratos e ao corroer o poder de compra da moeda.

Este estado de coisas explica a entrada do Estado, como substituto à iniciativa privada porque ele não vai à falencia, simplesmente imprime seus meios de pagamento ou financia suas atividades mediante o lançamento de títulos da dívida, com retornos superiores aos dos demais ativos em condições de incerteza $(6)$.

A retenção de dinheiro como forma de conservar a riqueza exige o pagamento de um prêmio quando se resolve desprender dele. A recompensa pelo não entrosamento, a ta$x a$ de juros é mais rígida a baixas que a recompensa de todos os outros bens, impondo um limite inferior ao investimento.

Os investimentos serão realizados enquanto a eficiência marginal de capital superar a taxa de juros monetária. A eficiência marginal do capital revela as expectativas de renda (monetária esperada) dos empresários.

Se a firma financia seus próprios investimentos a partir do fluxo de caixa e reinveste os lucros, ofluxo de rendas esperadas futuras (prognóstico mais provável) deverá cobrir o preço do bem de capital considerando o comportamento esperado da taxa de juros e o estado de confiança relativo a essas expectativas de longo prazo.

As previsőes traduzem as expectativas relativas ao futuro que embasam as decisões de atividade econômica, tanto no que se refere à composição do portfólio, quanto ao comportamento da produção, do investimento e do emprego. Do lado da produção, as expectativas de curto prazo determinam se a produção acabada será posta à venda ou não (Andrade, 1987).

No caso de reaplicação de recursos próprios não surgem problemas de demanda efetiva, pois o sistema financeiro das

(4) - A baixa elasticidade de produção é uma das três características da moeda, também é sinônimo de exogeneidade da moeda. Kalecki discorda dessa hipótese (Possas, 1987). Na década de 70, a tese da endogeneidade da moeda foi fortalecida com as evidências e as experiências paralelas de crescímento econômico e das taxas de inflação. Ver por exemplo, Bacha (1985) para o caso brasileiro. A interpretação mais recente de Keynes moderniza-o e acentua um grau maior de endogeneidade, que não estaria ausente nas obras anteriores de Keynes a exemplo do Tratado sobre a Moeda.

(5) - Para Minsky, a integração do lado real ao financeiro permite a Keynes apreender os problemas da instabilidade fínanceira. As raízes da instabilidade são forças endógenas ao sistema que refletem o processo de financiamento da atividade econômica. Segundo Minsky (1977. 1985) o sistema financeiro naturalmente instável tende a se tornar mais frágil com o desenvolvimento econômico, devido ao funcionamento da economia e não a erros da política econômica, Ver Mollo (1988).

(6) - Para maiores detalhes sobre os fundamentos da intervenção do estado em Keynes e Kalecki ver Cavalheiro (1987) 
economias modernas é robusto e o próprio Keynes considera que o investimento tem uma certa inércia devido ao amadurecimento diferido no tempo. Mas quando as firmas buscam recursos externos, o sistema pode colapsar pois muitas firmas constroem uma estrutura de endividamento frágil 7 ?.

A elevação da capacidade de alavancagem das firmas é possivel quando as firmas somam aos seus recursos internos, empréstimos tomados junto ao sistema financeiro que ampliam os recursos a serem investidos na ampliação da capacidade produtiva.

A parcela de pagamentos necessária para cobrir os serviços da dívida aumenta sempre em uma proporção superior ao fluxo de receitas à vista, quando ela ultrapassar a sua capa. cidade de endividamento, o que inviabiliza certos investimentos e leva as firmas a venderem seus ativos, para escapar a pre. juízos e honrar seus compromissos ${ }^{(8)}$.

A vulnerabilidade do sistema é amplificada, segundo Minsky (1977), quando surge algum fator interveniente que interrompe a expansão e há queda na oferta de crédito, na presença de crescente endividamento. A procura por liquidez se espalha pela economia e a partir da crise financeira surge a depressão e a passagem do tempo é fundamental para a sedimentação desse processo.

Para Andrade (1987, p.94)

\section{A tragédia das instituições financeiras em geral é que elas são úteis. Elas criam as condições para um bom funcionamento da atividade produtiva capitalista, ao mesmo tempo que está presente nelas próprias o blo- queio da natureza endógena que obstaculiza o investi- mento.}

O chamado motivo financiamento, a importância do tempo, a endogeneidade da oferta dos meios de financiamentos e as inovações financeiras permitirão aos pós-keynesianos como Minsky trilhar os caminhos de Keynes, sem falseá-10(9).

O ponto de partida é que o processo de investimento capitalista depende do alinhamento adequado entre os preços dos ativos de capital e os preços dos bens de investimento, o que dificilmente ocorre, pois os determinantes dos dois conjuntos de preços são muito diferentes.

Minsky (1977) co-responsabiliza as condições financeiras pelo não alinhamento e pela ausência de investimento, pois a moeda afeta diretamente o preço dos ativos de capital e dos ativos financeiros - e a preferência de portfólio e ofertas relativas - e indiretamente o preço dos produtos.

As condições financeiras lubrificam as engrenagens do sistema e fornecem impulso suplementar para ultrapassar a linha traçada pelas restrições orçamentárias dos capitalistas.
Se as condições forem favoráveis e há financiamentos, a elevação dos preços dos ativos de capital (PK) em relaçao aos preços dos bens de investimento $(\mathrm{Pi})$ ocorre, favorecendo os investimentos até que $\mathrm{Pk}$ iguale $\mathrm{Pi}$.

Os investimentos determinam a ocorréncia de lucros que permitirão aos capitalistas honrar seus compromissos financeiros. As condições necessárias para o bem funcionamento da economia são a existência de lucros, que entram na formação de expectativas dos lucros futuros, e condições financeiras favoráveis, pois a tomada de empréstimo possibilita o acesso a maiores lucros.

A endogeneidade da oferta de meios de financiamento surge em sistemas financeiros robustos a partir da interação entre a diversidade de instrumentos financeiros existentes, os bancos e os clientes, permitindo a substituição de moeda por ativos financeiros que financiarão o investimen to.

Segundo Mollo (1988, p.104), a fragilidade financeira crescente conduz ao enfraquecimento do sistema, pois

"O funcionamento dos bancos, endividando-se a curto prazo junto ao público e emprestando a longo prazo, e a aquisição de ativos financeiros pelo público correspondem a um aumento endógeno de moeda e de ativos líquidos. Tal aumento provoca a elevação dos preços de ativos de capital em relação à moeda, aos outros ativos líquidos e à produção corrente, le vando ao aumento da taxa de endividamento da economia".

Minsky (1977) define a fragilidade financeira a partir do grau de prudéncia do endividamento das unidades econômicas frente ao sistema financeiro. Define três tipos de unidades: Hedge, especulativas e Ponzi.

As unidades Hedge são aquelas cujo fluxo de caixa é sempre positivo, permitindo às empresas saldar seus compromissos financeiros e auferir lucros.

As unidades especulativas são aquelas cujo valor presente dos gastos é superior às receitas no curto prazo, mas há perspectivas favoráveis no longo prazo e as unidades podem se refinanciar desde que as taxas de juros não subam demais.

As unidades Ponzi são aquelas cujos fluxos de caixa no curto prazo é negativo, pois não cobrem os juros do principal no curso prazo; elas viabilizam-se no longo prazo na presença de baixas taxas de juros.

A tendência de fragilização financeira implica em uma estrutura financeira composta predominantemente de unidades econômicas de investimento especulativas e Ponzi. A explicação da endogeneidade remete às condiçoes que viabi-

(7) - Robinson (1988) afirma que a hipótese da fragilidade financeira de Minsky (1977) e a do endividamento crescente e a do ciclo político de Kalecki são complementares, pois a expansâo e o colapso do crédito atuam como ampliadores do ciclo político.

(8) - O conceito capacidade de endividamento está exposto em Kalecki, ver Possas (1987, cap. 3).

19) - Para maiores detalhes sobre o motivo financiamento ver Mollo (1988). Segundo a autora Keynes discorreu sobre o motivo financiamento em 1937, mas este passou despercebido nos meios académicos devido à síntese de Hicks, que eclipsou e deturpou muito a teoria Keynesiana. Há diferença entre demanda por dinheiro e demanda por crédito (financiamento) 
lizam o investimento financiado por empréstimos, equalizando $\mathrm{Pi}$ a $\mathrm{Pk}$, e ao caráter especulativo das próprias instituições financeiras e da rede bancária.

A fragilidade financeira se transforma em instabilidade quando as taxas de juros inviabilizam, não validam alguns dos investimentos que foram realizados durante o auge econômico e os bancos restringem a oferta de financiamento, quando a demanda por empréstimos e recursos financeiros é maior por parte das firmas endividadas.

Findo o período de tranquilidade, inicia-se outro, pleno de incertezas e caracterizado pela troca de papéis de longo para curto prazo e pela transformação de unidades hedge em unidades especulativas e de unidades especulativas em unidades Ponzi, que se tornam inviáveis.

A inelasticidade de oferta de meios de financiamento, ou seja crédito para os agentes econômicos, requer um reordenamento da economia e redefinição do papel das Autoridades Monetárias no sistema a hipótese keynesiana inicial é que o Banco Central seria independente ${ }^{(10)}$.

A instabilidade financeira é inerente e responsável pela instabilidade do capitalismo e os encadeamentos existentes estabelecem tendéncias ascendentes que favorecem a acumulação e fragilizam o sistema financeiro, conduzindo à quebra do padrão de crescimento e ao saneamento econômico dos agentes financeiros e produtivos.

O comportamento satisfatório da economia conduz a um "boom" de caráter especulativo que conduz à depressão, a partir da manipulação das equações da demanda por moeda e da fórmula de cálculo do preço de demanda dos ativos.

A atividade especulativa das instituições financeiras favorece a avaliação positiva de mercado das empresas e desvaloriza o prêmio de liquidez e o sistema financeiro sinaliza.

\begin{abstract}
às empresas um aumento de sua capacidade de gerarem fluxo de caixa meramente através da alienação de seu patrimônio, até que chega um momento em que a avaliação de mercado das empresas passa a não ter mais qualquer relação com suas condições objetivas de liguidez. O encurtamento das estru. turas passivas e a sua consequente fragilização é o "locus" onde se expressa essa situação. A reversão ocorre então, porque as empresas, ao tentarem suprir sua demanda de liquidez pressionam no sentido de venda dos ativos, iniciando, assim, a derrocada porque a sinalização enviada pelo sistema financeiro mostra afinal o que era, ilusão. (Paulani, 1988, p.30).
\end{abstract}

Minsky recupera o papel da incerteza e da instabilidade capitalista em Keynes, destaca a importância do conceito de liquidez na decisão de investir e demonstra a importância das relações financeiras e do estado vigente de liquidez para a explicação do ciclo econômico. Minsky, assim como Keynes, reitera a impossibilidade de substituir essa incerteza por proposições probabilísticas relevantes.
É necessário ressaltar que os conceitos de instabilidade e de crise em Keynes e nos pós-keynesianos são sustentados pela referência ao tempo. $O$ dinheiro é o refúgio que os agentes econômicos buscam para escapar das expectativas negativas referentes ao futuro e é a partir dele que se conforma um padrão cíclico de atividades econômicas.

Em Keynes é possível entender a lógica das flutuações da atividade económica a partir da lógica financeira, mas não há uma teoria do ciclo. Ela é desenvolvida posteriormente por Minsky, a partir da rede de intermediação financiera, que envolve pessoas físicas, empresas e bancos, cujo horizonte de cálculo diminue até decolar de sua base objetiva de sustentação.

Schumpeter desenvolveu uma teoria do ciclo calcada nos impactos primários e secundários de um conjunto de inovações concentrados no tempo. Mas súa teoria não reconhece os efeitos dinâmicos da demanda efetiva (Possas, 1987).

A síntese Keynes-Schumpeter permite o entendimen to da instabilidade capitalista e seu desdobramento temporal. Ela incorpora a análise de demanda efetiva de Keynes que aborda adequadamente o fenômeno da crise, à análise de Schumpeter cuja visão sobre a fase de crescimento a partir das inovações é essencial para compreender a fase ascendente do ciclo econômico.

\section{2 - A INSTABILIDADE EM SCHUMPETER}

A produção de mercadorias envolve a combinação de forças e coisas ao nosso alcance, mas como destaca Schumpeter (1982) as combinações econômicas diferem das tecnológicas. As primeiras estão relacionadas às necessidades e as últimas ligadas à idéia básica de métodos.

A tecnologia desenvolve métodos produtos para bens procurados, mas o verdadeiro corte é feito ao nível económico, pois a lógica econômica prevalece sobre a tecnológica, devido à existência de distorções como economias de escala, indivisibilidade da produção e externalidades na produção.

O fluxo circular em que se encontra a economia estacionária, mas não estagnada de Schumpeter - construção teórica utilizada para compreender o desenvolvimento - só é rompido se uma mudança técnica radical tornar-se economicamente viável, gerando a descontinuidade nas taxas de crescimento econômico.

O conjunto de inovações primárias tem o poder de sucatear a base técnica anterior, surge concentrado no tempo e dá início ao processo de destruição criadora. No seu rastro aparece uma onda de inovações secundárias, destinadas a elevar a eficiência das rotinas produtivas vigentes ou a ampliar o escopo dos princípios ordenadores da base técnica (Guimarães, 1986).

O surgimento de grandes mudanças técnico-economicas é intermediado pela função empresarial. O novo comportamento empresarial requer mudanças na rotina de to-

(10) - A hipótese de Kalecki é mais realista pois supõe moeda endógena e um Banco Central passivo que dispõe a amparar as unidades de produ. căo capitalis tas em suas necessidades por crédito. 
mada de decisões, implicando na escolha e na execução de estratégias que não estão configuradas nas rotinas dos gerentes e administradores e que são motivadas pelo lucro.

A mudança nos canais de rotina desorienta e muitos gerentes são incapazes de se adaptar a elas. A nova conduta só será imitada quando os frutos monetários das novas com. binações for apropriado pela função empresarial e tornar-se visível para os demais. Isto é, quando estas firmas começam a crescer e a acumular capital.

Shumpeter, (1982) ressalta que a principal característica desse sistema é estar em constante mutação. O elemento fundamental que permite a transformação, a mudança técnica, é endógeno ao sistema capitalista. A transformação descontínua e espontânea que provoca a destruição da base tecnológica anterior é possível porque as barreiras economicas, mentais e psicológicas anteriormente existentes são quebradas pela função empresarial (11).

Os elementos básicos da análise schumpeteriana são a inovação, que representa a idéia ou a nova combinação; o empresário, sujeito da mudança e o crédito bancário, meio que permite que a meta seja alcançada - disseminação generalizada da inovação.

A introdução do progresso técnico ocorre em três fa. ses: invenção-inovação-difusão (ou imitação pelos concorrentes). A inovação surge em ondas ou aglomerados concen. trados no tempo e é viabilizada pela figura do empresário inovador ${ }^{(12)}$.

A etapa de imitação ou difusão é caracterizada por um processo de ascenção, auge e descenso cíclico. A concorrência é acompanthada. pela centralização de capitais, gerando a partir da recessão as condições propícias (mas não suficientes) para o surgimento de uma nova onda de inovaç̃es $^{(13)}$.

O conceito de progresso técnico schumpeteriano abrange novos produtos, novos processos, novos mercados, novas formas de organização industrial, etc. Para realizar as novas combinações o empresário inovador recorre ao crédi. to fornecido pelos capitalistas, que cria poder de compra, principal fonte de financiamento das inovações $(14)$.

As atividades de investimentos derivadas da inovação schumpeteriana promovem ciclos economicos de intensidade e duração variados e explicam sua origem e evolução no mesmo ramo ou em ramos ligados direta ou indiretamente 1 (15).

O início e a continuidade do processo de investimentos em "novos métodos" que origina o novo ciclo só é possivel, quando única e exclusivamente ligado ao financiamento das novas idéias, mediadas pela função empresarial.

A tarefa do empresário, móvel da transformação, é demolir a velha tradição e criar uma nova, a partir do crédito que é criado passivamente pelo sistema, com o intuito de espalhar, magnificar os efeitos da transformação e induzir novos investimentos a partir do autônomo inicial. O desenvolvimento schumpeteriano é por natureza desarmônico, pois os setores onde a inovação é originalmente introduzida crescem a um ritmo muito superior ao do restante da economia. A concorrencia schumpeteriana em sentido lato proporciona que os capitais de outros setores afluam para o setor de crescimento mais acelerado, propiciando o aprofundamento das diferenças existentes $(16)$.

As inovações surgem em grupo, concentradas no tempo e têm um impacto vigoroso sobre o nivel de atividade

(11) - Schumpeter (1982) não obscurece em sua análise a existência de fatores externos ao sistema que podem perturbar temporariamente o equilfbrio económico como as guerras, as catástrofes e o crescimento populacional. Os elementos externos e outros fatores internos ao sistema econômico, a exemplo da alteração de gostos, das mudanças nos recursos produtivos entre outros, não permitem que a rota seja alterada de maneira permanente. O desequilíbrio gerado pela inovação não permite o retorno à situação de equilibrio anterior.

(12) - A invenção não é objetivo de estudo de Schumpeter porque seus determinantes estão fora do campo econômico, estão inseridos no âmbito da filosofia da ciencia. Toda invenção comercializada é uma inovação. Uma inovaçăo primária como a eletricidade pode gerar uma onda de crescimento económico porque sucateou as tecnologias anteriormente utilizadas como a lénha e o carvão. A difusáo dessa importante inovação nos diversos ramos económicos gera uma onda longa de crescimento, um ciclo de Kondratief.

(13) - A visão de Schumpeter contrasta com a de Mensch que sugeriu que são as crises e em particular as grandes depressões que favorecem o surgimento de inovações básicas. Mensch sugere que os perfodos depressivos reduziriam ao tempo de gestação entre as grandes invençốes e as inovações radicais, providenciando condições para fases de crescimento intenso e acelerado. A hipótese de Mensch não se sustenta para inovações radicais, mas é bem apropriada para explicar pequenas mudanças (Freeman, 1982).

(14) - O financiamento das novas combinações inclui o crescimento anual da poupança social e parte dos lucros não distribuldos aos acionistas, um fundo resultante de uma inovação bem sucedida que anualmente pode tornar-se livre. O esquema schumpeteriano não estabelece claramente as interações entre invençăo e inovação, e entre difusão e inovação. Para Schumpeter (1982) a invenção é um elemento exógeno e supõe um hiato temporal entre a mesma e a inovação, mas não possui uma teoria da invenção que "feche" o seu quadro teórico. Para maiores detalhes ver Guimarães (1986).

(15) - Cruz (1985) adverte que o impacto causado pelos investimentos da "onda secundária" são substanciais em ramos selecionados da economia, operando à semelhança do multiplicador keynesiano. Freeman (1982) enfatiza o papel das grandes descobertas cientítıas, reforçando o papel do enxame de inovações no crescimento. Sua teoria alternativa que sugere que as constelações de inovações básicas possuem elos de cunho científico, técnico, econômico e social, e que são acompanhadas por enxames de imitadores no processo de difusão dão origem a sistemas tecnológicos, base para a constituição das ondas longas de crescimento econômico.

(16) - A concorrencia capitalista que possibiłita o desenvolvimento e a transformação da estrutura econômica, dá lugar à concorrência de preços à médida que o processo de inovação se generaliza e os frutos da introdução do novo método não aparecem nas mãos dos indivíduos na magnitude que esperavam quando o introduziram. A concorrência de preços faz com que o organismo econômico tenda ao equilíbrio ao impelir os individuos a extraírem o maior proveito pessoal das possibilidades de lucro oferecidas por uma dada estrutura económica. Também funciona como um ponto de apoio para a tomada de decisões do homem de negócio. 
econômica, o setor bancário cria poder de compra e origina um processo de elevação de $\operatorname{preços}^{(17)}$.

A primeira versão do modelo cíclico de Schumpeter possui duas fases: prosperidade que é detonada pela introdução da inovação, desequilibrando o sistema de preços e recessão, que é deflagrada pela absorção dos efeitos do processo técnico pela economia que luta em busca de um novo ponto de equilíbrio, reduzindo o nível de preços.

A concorrência capitalista, que em um primeiro momento expande o nivel de atividade economica, posteriormente conduz à retração, é responsável pelo caráter de instabilidade próprio do capitalismo, também evidentes na obra de Marx "O Capital" e Keynes (1983). A introdução do progresso técnico desequilibra o sistema, enraizando a incerteza no funcionamento das empresas e, por, conseguinte, da economia como um todo.

Na fase de prosperidade, o clima de otimismo que se espraia pela economia cria novas empresas e revigora as antigas; a geração de expectativas otimistas para o futuro acompanha a especulação. A expansão da capacidade produtiva faz com que o produto das antigas e das novas empresas se confrontem no mercado, levando à guerra de preços que os rebaixa.

A redução da lucratividade das empresas operantes, devido à maturação dos investimentos reverte as expectativas e inicia a recessão das atividades produtivas, uma espécie de purgação pelos excessos cometidos na fase de prosperidade.

Neste meio tempo o empresário é obrigado a saldar suas dívidas e o vigor da concorrência capitalista elimina os lucros económicos das firmas novas e antigas e as empresas que se encontram em condições desfavoráveis de produção ficam expostas devido a erros de cálculo, pagamentos de dívidas, especulação excessiva e expansão da produção a custos não decrescentes. O processo de reajuste de preços leva ao redimensionamento da produção em algumas empresas e ao fechamento de outras.

No segundo modelo, Schumpeter (1939) incorpora os efeitos da onda secundária (imitação) e o processo se compõe de quatro etapas: prosperidade, recessão, depressão e recuperação. Neste segundo modelo Schumpeter (1939) destaca as condições imperfeitas de competição entre os diversos ramos e setores de produção que impossibilitam o crescimento equilibrado. O processo evolucionário pode aprofundar as diferenças entre os ramos pois coexistem ci- clos de diferente período de maturação: curta, média e lon. ga(18).

Schumpeter explica as crises em economias capitalistas a partir do esgotamento das opções oferecidas pelo enxame de inovações primárias e a onda de inovações secundárias que a ela se segue e justifica a ação de determinadas nações que buscam o mercado externo como alternativa para a realização de novas combinações que permitam a con. tinuidade do crescimento.

O comportamento expansionista dos países enraíza-se nos motivos econômicos. Schumpeter analisa os cartéis e trustes e os empreendimentos de larga escala - monopolistas de exportação e os casos puros.

Os pequenos grupos de capitalistas reúnem-se em trustes e cartéis para se lançarem no mercado externo, após alcançarem o produto ótimo ao nível ótimo de produção no mercado doméstico. Isto contribui para o crescimento da firma, gerando uma nova fonte de acumulação e possibilita a expansão do horizonte de mercado das demais firmas $\mathrm{e}$ portanto é uma estratégia que Schumpeter não condena.

Schumpeter concilia a racionalidade capitalista a políticas expansionistas ao analisar um outro caso de empreendimentos de larga escala. Este segundo grupo inclui um número crescente de firmas que operam dentro do mais puro espírito capitalista: as firmas schumpeterianas são inovadoras e sua capacidade de acumulação transcende os limites nacionais.

Os empreendimentos de larga escala denominados monopolistas de exportação procuram se beneficiar das políticas governamentais que asseguram lucros econômicos comportando desde políticas de proteção cambial até polf. ticas irracionais, como as guerras imperialistas. Tanto o comportamento irracional praticado pelas firmas deste terceiro grupo, quanto a pressão que ele exerce para a consecução de políticas governamentais imperialistas são condenados por Schumpeter (Cramer \& Leathers, 1977).

Schumpeter distingue a pequena da grande inovação e privilegia as grandes inovações, as médias e pequenas inovações têm menor importancia que a inovação primária.

A relevância da onda secundária no processo de acumulação em seu esquema é minimizada, mas são estas que garantem um fluxo de renda contínuo e de pequenas mutações a nível de processo e de produto que asseguram uma posição monopolista sob controle, menos temporária do que Schumpeter desejaria.

(17) - O processo inflacionário só estancará quạdo os novos produtos chegarem ao mercado, em função da expansão da capacidade produtiva e da concorréncia de preços. A inflação è irmá gêmea da liquidez que o sistema bancário proporciona aos setores que promovem a transformação. Schumpeter (1982) destaca que a estrutura creditícia se projeta além da base existente de ouro e de mercadorias. Os novos in vestimentos amadurecem, enquanto o fluxo de poder de compra criado pelos banqueiros, isto é, a injeça de dinheiro novo no mercado proporciona a realocação dos fatores de produção tradicionais de produção. O impacto inflacionário está relacionado à falta de elasticidade da oferta do setor produtivo em condições de pleno emprego e a concessão de crédito opera como um comando sobre os bens que necessita e confia-lhes forças produtivas. Surge o que Schumpeter classifica de poupança forçada, dada a ausência ou insuficiência de poupanças prévias que financiem em sua totalidade as novas combinaçốes. O empresário usa o novo poder de compra para retirar do fluxo circular os fatores que necessita, para realizar o novo produto vaí recombiná-los, gerando aumento de preços, isto é, inflação e há compressão do poder de compra existente.

(18) - A duração dos ciclos está associada a inovações de diferentes graus de impacto sobre a estrutura positiva. Segundo Clemence \& Doody (1966), os ciclos de ordem superior condicionam os ciclos de ordem inferior e uma inovação que implique em uma onda larga permanecerá problematizada até que tenham sido absorvidos os efeitos da inovação que engendrou a onda larga anterior. 
O desequilibrio econômico - entendido como a aceleração das taxas de crescimento - gerado pela introdução de uma inovação de grande amplitude é fonte de acumulação e de crescimento capitalistas.

Para manter uma fonte inesgotável de crescimento é preciso, também uma fonte contínua de lucros e a única que poderá proporcionar esta condição - independentemente de barreiras e imperfeições que possam permear o sistema - é a inovação.

As grandes invenções que revolucionam o sistema não estão sob o controle do capital e portanto não é possivel aplicar mecanisticamente a regra e há alternância entre crescimento e estagnação e a periodicidade de ambos não pode ser estabelecida ${ }^{(18)}$.

A tendéncia ao equilíbrio projetada por Schumpeter jamais se concretiza, pois o processo de adaptação de cada firma, indústria, ramo, setor obedece a determinantes diferentes e o desequilíbrio é norma tanto na fase ascendente, quanto descendente do ciclo.

A apropriação dos frutos das inovações não é suficiente para garantir a total realização da massa de lucros de uma empresa inovadora em setores oligopolizados, pois ela cresce a um ritmo superior ao das rivais e em determinadas ocasiōes superior à própria demanda. Daí a necessidade de instrumentos legais como a garantia das patentes e a expansão dos horizontes geográficos das firmas.

O processo de internacionalização do capital é consequência da sobreacumulação nacional, dando origem às empresas multinacionais. Inúmeras teorias dentro do escopo da teoria do comércio internacional buscam explicar essa trajetória(19).

Se a explicação schumpeteriana é satisfatória para ex plicar por que há um ambiente favorável que estimula o surgimento e a disseminação de inovações que promovem ciclos de crescimento, a hipótese referente às fases recessivas. Schumpeter reconhece que o retorno ao equilíbrio ocorre devido à queda da lucratividade e da atratividade dos inves- timentos adicionais, mas não explora a fundo a questão(20).

A fragilidade de Schumpeter é a explicação para o fenômeno das crises, por que cessam os investimentos que induzem a novas ondas de crescimento? A explicação de que as crises ocorrem na ausencia de um cluster de inovações que gerem nova onda de crescimento, pois as demais inovações "lato senso" tem caráter temporário não satisfaz diversos autores $(21)$

A literatura denominada neo-schumpeteriana centra a inovação técnica como principal fonte de crescimento e transformação econômico-institucional das economias capitalistas. Freeman 1982, Dosi 1984, Nelson \& Winter 1977 e outros. restabelecem a inovação enquanto principal dinamizador da atividade econômica capitalista e ressuscitam Schumpeter, uma vez que a literatura econômica o esque. ceu por uns 40 anos.

Rosenberg apud Guimarães (1986) critica a sequência invenção-inovação-difusão, cujas etapas não seriam tão estanques quanto Schumpeter destacou. As inovações primárias que -desencadeiam o processo de destruição criadora normalmente são derivadas de inovações secundárias anteriores. $E$ as inovações secundárias que aumentam a eficiência das rotinas produtivas e técnicas fazem parte do processo de difusão.

Para Rosenberg, a própria atividade de P\&D é uma fonte de crescimento da produtividade, pois as diversas etapas do processo de inovação formam um processo contínuo, cujos intervalos são preenchidos pelas atividades de pesquisa que buscam incrementar a eficiência e agilizar a rotina produtiva e técnica que faz parte do processo de difusão (Guimarães, 1986).

A inexistência da exploração dos fatores institucionais frente à mudança e a difícil adaptação dentro do novo quadro tecnológico é outra lacuna. A hipótese básica de Perez (1982) é que as depressões são perfodos que se inter-

(19) - A conclusão do estudo sobre as ondas longas de Mandel (1980) indica que não há modelo econométrico ou mesmo histórico que proporcione uma previsão ex-ante satisfatória, pois estão calcados justamente em uma certa regularidade comportamental das variáveis analisadas.

(20) - Ver a teoria do ciclo do produto em Vernon (1966).

(21) - Segundo Freeman $(1982$, p. 73-80) a evidência empírica a respeito das grandes trajetórias naturais de tecnologias na história - denominados ciclos de Kondratief: inovações no setor téxtil/a vapor; ferrovias e aço; eletricidade/motor a combustão/química; eletrônica - não f́ adequada, mas reforça o ponto defendido por Schumpeter de que uma inovação básica, seguida de um pequeno exame de inovaḉes básicas relacionadas criam possibilidades revolucionárias nos métodos de produção de uma vasta gama de indústrias e serviços. A exploração de economias de escala, como sugerem Nelson \& Winter (1977) também está por trás do processo de surgimento, crescimento, maturação e em alguns casos até mesmo declínio de alguns setores industriais - sugerindo todo um processo de exploração das potencialidades da inovação básica. A maturação da indústria associa-se à queda/redução da lucratividade, oportunidade e atratividade de investimentos adicionais.

(22) - Os autores neo-keynesianos, Minsky (1975) e Chick (1983) salientam o fenômeno das crises financeiras, fru to de movimentos especulativos, que condicionam e obstaculizam o investimento em economias capitalistas em determinadas fases do ciclo económico. Nesta primeira vertente, procura-se salientar a importância da ação estatal no processo, ao estimular/fomentar instituições de pesquisa (Possas, 1987).

Outra corrente descarta as crĭses financeiras, enquanto questão fundamental, pois este é um fenômeno de curto prazo e levanta que as crises estruturais problematizam os novos investimentos. A inspiração provém de Marx que se preocupou basicamente com as leis de movimento e as tendéncias evolutivas do modo de produção capitalista. O progresso técnico entre como uma variável para se contrapor à tendencia histórica do declínio da taxa de lucro e há espaço para a discussão das crises sistêmicas e das crises institucionais do capitalismo. Para maiores detalhes sobre as crises sistêmicas e institucionais do capitalismo recorrer a Habermas (1980), Perez (1982), Mandel (1980), Mazzucchelli (1985), Guimarães (1986), Possas (1987), entre outros. 
põem entre o novo paradigma tecnológico e o quadro institucional e socialmente no qual este se difunde.

A mudança técnica ao nível microeconômico processa-se rapidamente, mas ao nível macroeconômico há elevado grau de inércia das instituições sociais. Segundo Perez (1982) proliferam os esforços de resistência às transformações dos grupos ligados às indústrias em decadência e às tecnologias que entram em desuso e que se sentem ameaçados de extinção. Há tentativas de encontrar soluções políticas e sociais adequadas aos problemas de adaptação institucional que surgem.

\section{3 - NOTAS CONCLUSIVAS}

A busca de elementos dentro da teoria econômica que permitissem esclarecer e compreender a característica sistêmica e endógena do sistema capitalista, a instabilidade, conduziu à leitura de Keynes e Schumpeter.

Keynes (1983) ressalta a importância do tempo - negligenciado na análise dos autores que o procederam - nas decisões dos agentes económicos, assim como na presença de expectativas na tomada de decisões, introduzindo um componente de incerteza (flutuante) na maioria das decisões pertinentes à economia.

A incidencia de expectativas incertas é mais premente nas decisões de investir e produzir e na escolha do grau de preferência pela liquidez. Tais decisôes possuem um caráter monetário e envolvem expectativas; logo, as malhas da incerteza e consequentemente da instabilidade se estendem por toda a economia, através dos sistemas bancário e financeiro.

A presença da incerteza confere significativa importância ao presente, pois tanto as decisões de investir, quanto produzir e vender não são infinitamente elástiças, possuem certa inércia, não podendo ser revertidas no tempo.

O reconhecimento da moeda como reserva de valor, fonte de instabilidade, assim como o estabelecimento de contratos em valores monetários, fonte de estabilidade, re. Hetem o caráter contraditório do dinheiro no modo de produção capitalista.

Por fim, a relevância dos acontecimentos presentes e do passado pouco distante - dando um certo caráter de convencionalidade - nas decisões de investir e produzir e vender é a marca registrada da análise keynesiana.

A ênfase que a escola keynesiana dá ao caráter especulativo do investimento, relega a um plano secundário outra importante fonte de instabilidade dentro do capitalismo, a existência da concorrencia que leva os capitalistas dentro de uma lógica própria a decidirem pela manutenção, expansão e criação de mercados e cujo papel é também fundamental nas decisões de investimento.

Neste prisma destaca-se a visão de Schumpeter (1982) que alertou os economistas para a ocorrência de mudanças técnicas radicais e inesperadas que delineam o desenvolvimento econômico capitalista e que se caracterizam por uma lógica diferente da concorrencia via preço. Outra importante mensagem schumpeteriana é que a inovação é um fenómeno endógeno ao sistema capitalista.

A atividade econômica caracteriza-se por movimentos cíclicos, que tendem ao referencial de equilibrio - estacionário, mas não estagnado - devido à presença da concorrênde preços. Este movimento interrompe-se na presença de clusters de inovações que se concentram no tempo e desencadeiam investimentos diretos (primários) e indiretos (secundários) - bandwagon.

A presença dessas mudanças técnicas que têm o poder de revolucionar e sucatear a base técnica vigorante, ocasio. na investimentos cujas maturações são diferidas no tempo e ocasionam as ondas longas de crescimento. A reversão no processo ocorre quando há ausência de inovaçōes de caráter significativo que motivem a decisão de investir.

A semelhança de Keynes, Schumpeter descreve um processo que se caracteriza não só pela fase da prosperidade que possibilita a busca desenfreada pelo aproveitamento das possibilidades de investimento que se oferecem de imediato, mas também pela depressão.

As duas óticas são complementares, a visão schumpeteriana nos propicia elementos para compreender adequadamente o porquê da fase de prosperidade do ciclo econômico e a ótica da demanda efetiva keynesiana enriquece a teoria econômica ao discurir os elementos que ocasionam a fase de crise e retração, consubstanciando movimentos cíclicos, flutuações irregulares ao longo do processo de desenvolvimento econômico.

\section{ABSTRACT}

Instability is an important systemic characteristic of capitalism. This article aims at discussing Keyne's and Schumpeter's wew of the origins of instability and tries to integrate their approach on the economic cycle in clear speech.

KEY-WORDS: Economic instability; Development and crisis; Economic cycle; Schumpeter, Keynes.

REFERENCIAS BIBLIOGRÁFICAS

1 - ANDRADE, R.P. Expectativas, incerteza e instabilidade no capitalismo: uma abordagem a partir de Keynes. $R E P$, $7(2)$ : 81-95, abr-jun, 1987.
2- BACHA, E. Introdução à macroeconomia: uma perspectiva brasileira. 3. ed. Rio de Janeiro: Ed. Campus, 1985. 
3-CARVALHEIRO, N. Fundamentos da Intervenção do Estado: algumas concepçóes em Keynes e Kalecki. REP, 7(2): 195-122, abr-jun, 1987.

4- CARVALHO, F.C. A Atualidade do Pensamento Keynesiano: Instabilidade, Crise e Valorizaça Financeira. In: SEMINARIO SOBRE O CINOUENTENÁRIO DA TEORIA GERAL DE KEYNES. Anais... Vitória: UFES, Depto. de Economia, 1986, p. 84-102.

5. CHICK, V. Macroeconomics after Keynes: A Reconsideration of the General Theory. Cambridge: MIT Press, 1983.

6 - CLEMENCE, H. \& DOODY, S. The Schumpeterian System. New York: Kelley, 1966

7. CRAMER, D. \& LEATHERS, C. Veblen and Schumpeter on Imperialism. HPE, 9(2):237-255, 1977.

8 - CRUZ, H.N. Schumpeter e os Desafios do Setor Industrial Brasileiro. In: BRAS/L 1980. São Paulo: IPE/USP, 1985 p. $175-190$.

9 - DOSI, G. Technology and Conditions of Macroeconomic Development. In: FREEMAN, C. (Ed.) Design, Innovation and Long Cycles in Economic Development. New York: St. Martin's, 1984. p. 60-78.

10- FREEMAN, C. The Economics of Industrial /nnovation. 2 ed London: Frances Pinter, 1982.

11- GuIMARÃES, F.C. A Política Tecnológica nos Paises de Industrializaç̃o Recente. Rio de Janeiro: IEl-UFRJ, 1986 (Texto para discussão n. 98 )

12 - HARERMAS, J. A Crise de Legitimação no Capitalismo Tardio. Rio de Janeiro: Tempo Brasileiro, 1980.

13 - HICKS, J. Mr. Keynes and the Classics: A Suggested Interpretation. Econométrica, 5, April 1937

14 - HICKS, J. The Crisis in Keynesian Econonics. New York: Basic Books, 1974.

15 - HICKS, J. Economic Perspectives - Further Essays on Money and Growth. London: Oxford University, 1977.

16 - KALECKI, M. Theory of Economic Dynamic. 2 ed. London: Allen \& Unwin, 1954

17 - KEYNES, J.M. Teoria Geral do Emprego, do Juro e do Dinheiro. São Paulo: Abril Cultural, 1983. Traduzido do original inglês de 1936

18 - MANDEL, C. Long Waves in Capitalist Development: The Marxist Interpretation. New York: Cambridge University Press, 1980.
19 - MAZZUCHELLI, F. A Contradicão em Processo. O capitalismo e suas Crises. São Paulo: Brasiliense, 1985.

20 - MINSKY, $H$. The Financial Instability Hypothesis: a Reestatement. In: ARESTES, P. (ed.) Post Keynesian Economic Theory. Athens: T. Skouras, 1985.

21- MINSKY, H. A Thoory of Sistemic Fragility. In: AlLTMAN \& SAMETZ (ed.). Financial Crisis. Now York: John Willey and Sons, 1977.

22 - MINSKY, H. John Maynard Keynes, New York: Columbia University Press, 1975.

23 - MOLLO, M.L. Instabilidade do Capitalismo, Incerteza e Pape das Autoridades Monetárias: Uma Leitura de Minsky. REP, 8(1): 100-123, jan-mar, 1988.

24 - NELSON, A \& WINTER, S. Forces Generating and Limiting Concentration under Schumpeterian Competition. The Bell Journal of Economics, 524-548, Autum, 1977.

25 - PAULANI, L.M. O Dinheiro, esse Obscuro Objeto. Seminários Internos dos Alunos de Pós-Graduação do IPE/USP. São Paulo: IPE/USP, 1988.

26- PEREZ, C. Structural Changes and Assimilation of New Technologies in the Economic and Social System. In: FREEMAN, C. (ed.) Design Innovation and Long Cycles in Economic Development. New York: St. Martin's, 1982 o. $27-48$.

27 - POSSAS, M.L. Dinámica da Economia Capitalista. São Paulo: Brasiliense, 1987.

28 - POSSAS, M.L. Em Direçăo a um Paradigma Microdinâmico: A Abordagem Neo-Schumpeteriana. Campinas: PNPE/ ANPEC, 1988.

29 - ROBINSON, J. Novas Contribuicóes a Economia Moderna. São Paulo: Abril Cultural, 1938. (Traduzido do original em ingles de 1982).

30- SCHUMPETER, J. A Teoria do Desenvolvimento Econômico. São Paulo: Abrii Cultural, 1982. (Traduzido do original em inglês de 1934).

31 - SCHUMPETER, J. Capitalismo, Socialismo e Democracia. Rio de Janeiro: Zahar, 1984. (Traduzido do original em inglês de 1943).

32 - SCHUMPETER, J. Business Cycles. New York: McGraw-Hill Book Company, 1939.

33 - VERNON, R. International Investment and International Trade in Product Cycle. $Q J E, 80(2), 1966$.

Recebido para publicaç̃o 25/3/1991 